\title{
Prognostic Impact of the Metastatic Lymph Node Ratio on Survival in Rectal Cancer
}

\author{
Wafi Attaallah, Omer Gunal, Manuk Manukyan', Gulden Ozden, Cumhur Yegen \\ Department of General Surgery, Marmara University School of Medicine, Istanbul; ${ }^{1}$ Department of General Surgery, Maltepe University \\ School of Medicine, Istanbul, Turkey
}

Purpose: Lymph-node metastasis is the most important predictor of survival in stage III rectal cancer. The number of metastatic lymph nodes may vary depending on the level of specimen dissection and the total number of lymph nodes harvested. The aim of this study was to evaluate whether the lymph node ratio (LNR) is a prognostic parameter for patients with rectal cancer.

Methods: A retrospective review of a database of rectal cancer patients was performed to determine the effect of the LNR on the disease-free survival (DFS) and the overall survival. Of the total 228 patients with rectal cancer, 55 patients with stage III cancer were eligible for analysis. Survival curves were estimated using the Kaplan-Meier method. Cox regression analyses, after adjustments for potential confounders, were used to evaluate the relationship between the LNR and survival.

Results: According to the cutoff point 0.15 (15\%), the 2-year DFS was $95.2 \%$ among patients with a LNR $<0.15$ compared with $67.6 \%$ for those with $\mathrm{LNR} \geq 0.15(\mathrm{P}=0.02)$. In stratified and multivariate analyses adjusted for age, gender, histology and tumor status, a higher LNR was independently associated with worse DFS.

Conclusion: This study showed the prognostic significance of ratio-based staging for rectal cancer and may help in developing better staging systems. LNR $0.15(15 \%)$ was shown to be a cutoff point for determining survival and prognosis in rectal cancer cases.

Keywords: Rectal neoplasms; Lymph nodes; Prognosis; Survival

\section{INTRODUCTION}

Colorectal cancer is the third most frequently diagnosed cancer in both men and women and the second most fatal cancer [1]. The most important determinant of the prognosis in patients with nonmetastatic rectal cancer is mesenteric lymph node involvement. The presence of lymph node involvement allocates the rectal cancer patient to stage III according to the American Joint

Received: February 25, 2013 - Accepted: May 1, 2013

Correspondence to: Wafi Attaallah, M.D.

Department of General Surgery, Marmara University Pendik Teaching and

Research Hospital, Ust Kaynarca, Pendik, Istanbul, Turkey

Tel: +902166570606, Fax: +902166570695

E-mail:drwafi2003@yahoo.com

(c) 2013 The Korean Society of Coloproctology

This is an open-access article distributed under the terms of the Creative Commons Attribution NonCommercial License (http://creativecommons.org/licenses/by-nc/3.0) which permits unrestricted non-

commercial use, distribution, and reproduction in any medium, provided the original work is properly cited.
Committee on Cancer Staging System and the European Society for Medical Oncology [2, 3]. Guidelines suggest adjuvant chemotherapy and/or radiotherapy for N1 and N2 patients [4]. Although a lymph-node-negative tumor suggests a good prognosis, how the number of positive lymph nodes affects survival is a subject of debate. It has been suggested that at least 12 lymph nodes need to be removed within the specimen for accurate staging [5]. However, the National Comprehensive Cancer Network's (NCCN's) guideline for rectal cancer suggests preoperative chemotherapy and or radiotherapy for node positive patients. The NCCN proposes a postoperative adjuvant therapy for patients with medical contraindications to combined modality therapy [2]. Recent publications have suggested substantial variations in nodal staging attributable to surgical, pathological, and patient factors [6]. These clinicopathologic factors may affect the number of lymph nodes harvested during the surgical and/or pathological dissection. This may result in inaccurate staging and subsequent inappropriate therapy. However, some researchers believe that TNM staging 
may not be optimal and have proposed alternative lymph-node parameters [7].

The metastatic lymph node ratio (LNR) is defined as the ratio of metastatic lymph nodes to the number of total lymph nodes pathologically examined. This figure seems to be superior to the absolute number of metastatic lymph nodes in predicting the prognosis and to be useful in reducing stage migration in types of solid cancers such as cancers of the stomach [8-10], breast [11], bladder [12], pancreas [13], and lung [14]. Many clinical studies on colorectal cancer patients have been performed to investigate the significance of the LNR as a prognostic factor [13, 15-20]. However, the clinical significance of the LNR in rectal cancer patients' survival is still controversial. Some researchers found no correlation between the LNR and the survival rate [21] while others concluded that the LNR was a more critical prognostic factor than simple lymph-node metastasis [22]. Therefore, we aimed to investigate whether the LNR is a better prognostic factor than the absolute number of metastatic lymph nodes in cases of stage III rectal cancer. Also, we searched for a cutoff value of the LNR for predicting a prognosis for patients with rectal cancer.

\section{METHODS}

A retrospective review of a prospectively-collected database of rectal cancer patients operated on between March 2000 and December 2011 was performed to determine the effect of the LNR on disease-free survival (DFS) and overall survival (OS). A total of 228 patients underwent an operation due to rectal cancer, 85 of which were found to be in stage III. The study was basically conducted on stage III rectal cancer patients. All patients had received adjuvant chemotherapy. Patients who received neoadjuvant chemotherapy and/or radiotherapy and patients who did not receive adjuvant chemotherapy or radiotherapy were excluded. Fifty-five patients with stage III rectal cancer who fit these criteria were included in this study. All patients were staged preoperatively by using computed tomographic (CT) scans only. In some patients, magnetic resonance imaging or positron emission tomographyCT scan were added to preoperative evaluation, if needed. Parameters such as age, gender, type of surgery, preoperative careinoembryonal antigen (CEA) levels and adjuvant therapy were analyzed. Tumors were assessed for histological type, grade, stage, vascular invasion, lymphatic invasion and perineural invasion. The number of examined lymph nodes, the number of determined metastatic lymph nodes and the LNR were calculated for each patient. Recurrences and distant metastases were also documented.

All patients underwent a standard total mesorectal excision (TME) and a regional lymphadenectomy with tumor-free surgi$\mathrm{cal}$ and circumferential margins. High ligation was performed in all patients as a routine procedure at our clinic. Lymph nodes in the specimen were recovered by in vitro mesenteric dissection. Data on lymph node status were obtained from pathology reports. Tumors were staged according to the current American
Joint Commission on Cancer (AJCC) TNM staging system. A combination of chemotherapy and radiotherapy was provided postoperatively to all patients. The postoperative adjuvant chemotherapy started within 2-4 weeks after the surgery and was given for 5 days every month by bolus infusing 5 -fluorouracil and leucovorin six times. Radiotherapy began on the first day of the third cycle of intravenous chemotherapy, and fractionated irradiation of the whole pelvic cavity with a dose of 4,500-5,000 cGy was conducted.

Recurrence, whether loco-regional or distant, was confirmed histologically or clinically (palpable mass or tumor that may be associated with clinical deterioration identified on imaging studies and verified with increased serum CEA level). The survival analysis was performed using the Kaplan-Meier method. Cox regression analyses, after adjustment for potential confounders, were used to evaluate the relationship between the LNR and survival. A statistically significant difference was assumed if the Pvalue was less than 0.05 .

\section{RESULTS}

Fifty-five patients with stage III rectal cancer who underwent a curative resection were evaluated. Demographic data, histopathological characterisitcs, and tumor characteristics for patients are presented in Table 1. Tumor grades from pathology reports were unavailable for two patients. The mean age of the patients was $60.33 \pm 13.3$ years. Thirty $(55 \%)$ were male and $25(45 \%)$ were female. All patients were diagnosed as having an adenocarcinoma. The median follow-up for all patients was 24 months (range, 1 to 145 months). The median number of recovered lymph nodes was 13 (range, 12 to 53). An analysis of the data showed the median LNR value to be $23 \%$. The study population was divided into 2 groups according to the LNR cutoff value of $23 \%$. One group consisted of patients for whom the LNR was greater than or equal to $23 \%$ LNR. The second group consisted of patients for whom the LNR was lower than 23\%. In Kaplan-Meier analysis, no significant difference was found between the 2 groups in terms of OS and DFS at the 1st, 2nd, 3rd, 4th, and 5th year after surgery.

The LNR values lower than $23 \%$ were analyzed for each patient in descending order to find a cutoff value that resulted in a significant difference between the two groups. The OS and the DFS were compared between the two groups for each LNR value to find a cutoff value of the LNR that affected OS or DFS. Only for a LNR value of $\leq 15 \%$ was the two-year DFS significantly better than it was for patients with a LNR of greater than $15 \%$ (19.41 \pm 1.3 months [67.6\%] and $23.03 \pm 0.9$ months [95.2\%], respectively, $\mathrm{P}=0.02$ ) (Fig. 1). When a multivariate Cox analysis for two-year DFS was done, we noted that none of the covariates affected the outcome (Table 2). Thus, the LNR 15\% as a cutoff point was found to be an independent factor for predicting the two-year DFS in patients with stage III rectal cancer.

We noticed that all patients with LNR $<15 \%(\mathrm{n}=21)$ had a 
Table 1. Demographics and histopathological characterisitcs of patients $(\mathrm{n}=55)$

\begin{tabular}{lc}
\hline Characterisitc & Value \\
\hline Age (yr), mean \pm SD & $60.33 \pm 13.3$ \\
Gender & \\
$\quad$ Male & $30(54.5)$ \\
Female & $25(45.5)$ \\
Retrieved lymph nodes, median (range) & $13(11-53)$ \\
Grade & \\
1 & $3(5.5)$ \\
2 & $38(69.1)$ \\
3 & $7(12.7)$ \\
Mucinous & $5(9.1)$ \\
Missed & $2(3.6)$ \\
pT stage & \\
T1 & $0(0)$ \\
T2 & $2(3.6)$ \\
T3 & $45(81.8)$ \\
T4 & $8(14.5)$ \\
Vascular invasion & $26(47.3)$ \\
Lymphatic invasion & $40(72.7)$ \\
Perineural invasion & $22(40.0)$ \\
\hline Follow-up, median (range) & $24(1-145.5)$ \\
\hline
\end{tabular}

Values are presented as number (\%) unless otherwise indicated.

stage $\mathrm{pN} 1$ tumor, but the patients with $\mathrm{LNR} \geq 15 \%(\mathrm{n}=34)$ included both stage $\mathrm{pN} 1$ (13 patients) and $\mathrm{pN} 2$ (21 patients) tumors. We also found that the patients with a stage $\mathrm{pN} 1$ tumor and LNR $\geq 15 \%$ had a two-year DFS of $61.5 \%$ (18.6 \pm 1.9 months). However, the patients with a pN1 tumor and LNR $<15 \%$ had a better two-year DFS of $95.2 \%(23.0 \pm 0.95$ months, $\mathrm{P}=0.023)$ (Fig. 2). Interestingly, the two-year DFS rate for LNR $>0.15$ in patients with a $\mathrm{pN} 1$ tumor was not statistically significantly better than that for LNR > 0.15 in patients with a pN2 tumor $(61.5 \%$ and $71.4 \%$, respectively, $\mathrm{P}=0.76$ ) (Fig. 3).

\section{DISCUSSION}

Lymph-node metastasis is one of the most important prognostic factors in rectal cancer. Although the significance of number of retrieved lymph nodes has increased [23, 24], some have pointed out that the current $\mathrm{N}$ staging, which depends on the number of metastatic lymph nodes, does not reflect the prognosis accurately $[25,26]$. Moreover, the number of retrieved lymph nodes is a variable that is affected by many factors including the individual characteristics of the patient, the competence of the surgeon, the ability of the pathologist to isolate and collect lymph nodes [27, 28], and the administration of neoadjuvant radiotherapy and/or che-
Table 2. Multivariate Cox analysis for 2-years disease-free survival $(\mathrm{n}=55)$

\begin{tabular}{lccc}
\hline Variable & $\begin{array}{c}\text { LNR } \geq 0.15 \\
\text { group }(\mathrm{n}=34)\end{array}$ & $\begin{array}{c}\text { LNR }<0.15 \\
\text { group }(\mathrm{n}=21)\end{array}$ & P-value \\
\hline Mean age (yr) & 60.30 & 60.38 & 0.72 \\
Sex, $\mathrm{n}(\%)$ & & & 0.58 \\
$\quad$ Female & $20(59)$ & $5(24)$ & \\
$\quad$ Male & $14(41)$ & $16(76)$ & \\
Mean retrieved lymph nodes & 16 & 17 & 0.34 \\
Grade & & & 0.61 \\
1 & 1 & 2 & \\
2 & 23 & 15 & \\
3 & 4 & 3 & \\
Mucinous & 5 & 0 & \\
Missed & 1 & 1 & \\
pT stage & & & \\
T1 & 0 & 0 & \\
T2 & 2 & 0 & 0.19 \\
T3 & 29 & 16 & \\
T4 & 3 & 5 & 0.47 \\
Vascular invasion, $\mathrm{n}(\%)$ & $17(50)$ & $9(43)$ & \\
Lymphatic invasion, $\mathrm{n}(\%)$ & $24(71)$ & $16(76)$ & \\
Perineural invasion, $\mathrm{n}(\%)$ & $10(48)$ & $12(32)$ & 0.08 \\
\hline
\end{tabular}

LNR, lymph node ratio.

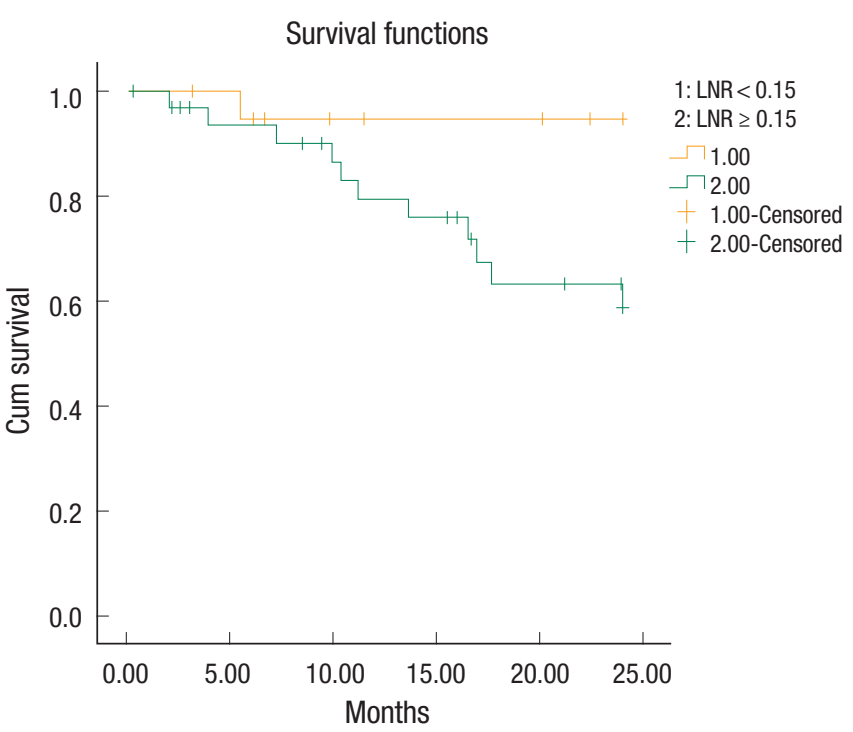

Fig. 1. The 2-year disease-free survival in stage III rectal cancer was significantly better in the lymph node ratio (LNR) $<15 \%$ group than it was in the LNR $\geq 15 \%$ group $(95.2 \%$ and $67.6 \%$, respectively, $\mathrm{P}=$ 0.02 ). 


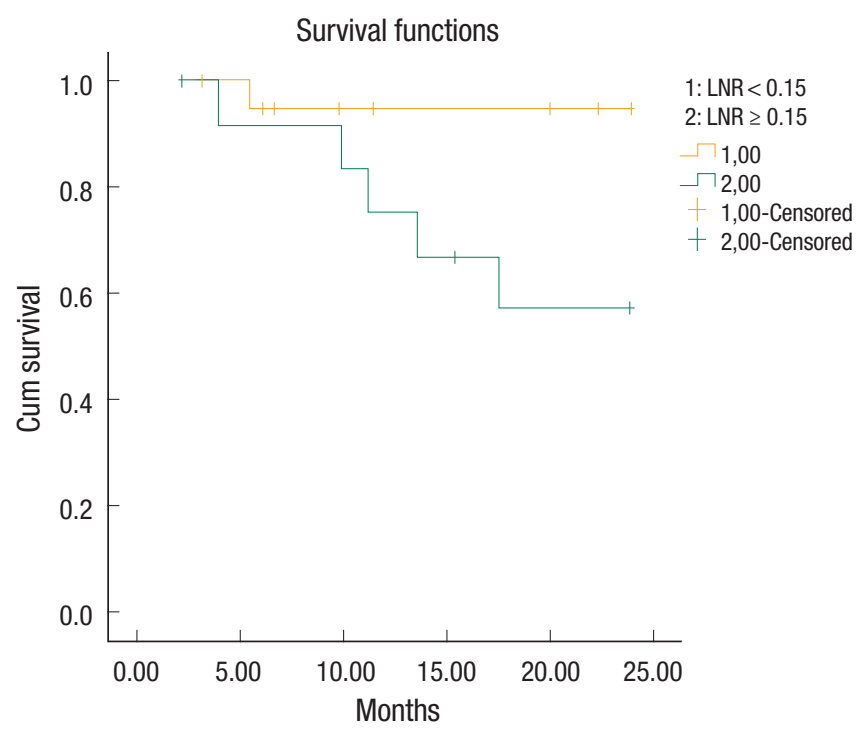

Fig. 2. The 2-year disease-free survival for patients in the $\mathrm{pN} 1$ and lymph node ratio (LNR) $<15 \%$ subgroup was significantly better than that for patients in the pN1and LNR $\geq 15 \%$ subgroup $(95.2 \%$ and $61.6 \%$, respectively, $\mathrm{P}=0.023$ ).

motherapy [29]. Therefore, a better prognostic classification system is necessary to minimize the influence of the number of collected lymph nodes and to supplement the limitations of the current TNM system. This would also provide a more accurate disease staging, which would allow more appropriate adjuvant treatment planning and better calculation of the long-term prognosis for stage III colorectal cancer patients [30].

Because the survival rate for stage III rectal cancer varies widely $[26,29,31]$, the clinical role of the LNR as a biologic predictor of prognosis has been demonstrated in some studies [18, 22, 32-35]. The present study investigated the LNR as a prognostic parameter for patients with stage III rectal cancer. Previous studies on the LNR for rectal cancer $[33,35,36]$ determined cutoff values based on quartiles or complex statistical methods, so their results were difficult to apply in daily clinical practice. That is the reason we tried to identify a single cutoff value for the prognostic stratification by dividing all patients into two groups according to a certain LNR value. Unlike patients with colon cancer, patients with rectal cancers are routinely considered for neoadjuvant chemo/radiotherapy before undergoing surgical resection. Besides shrinking the primary tumor and reducing the risk of local recurrence after surgery, radiotherapy may also decrease the number of local lymph nodes [37]. As a consequence this may decrease the number of lymph nodes retrieved, which may negatively affect the LNR values. Because of that, in this study, we did not include patients who had received neoadjuvant chemo/radiotherapy; thus, we were able to achieve more accurate ratio-based staging.

Reasons for not administering neoadjuvant chemo/radiotherapy in our study group were unavailability of radiotherapy, preopera-

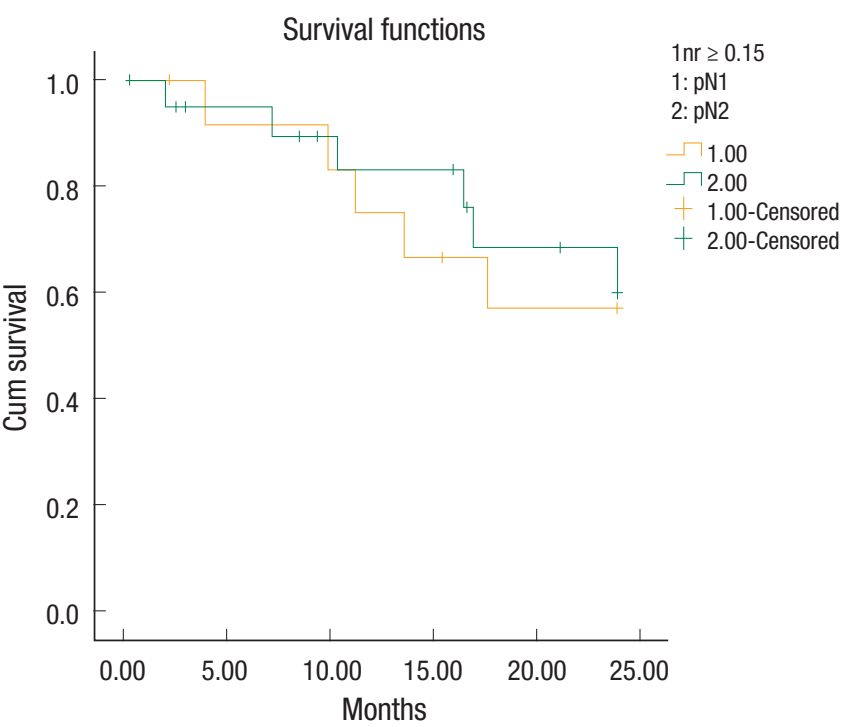

Fig. 3. The 2-year disease-free survival rate for lymph node ratio $>0.15$ in $\mathrm{pN} 1$ was not statistically significantly better than that in pN2 $(61.5 \%$ and $71.4 \%$, respectively, $\mathrm{P}=0.76)$.

tive mis-staging, patient's refusal, and surgeon's preference. This made our study population distinctive. All the patients included in this study were operated on by using the TME technique and received adjuvant chemo/radiotherapy after surgery. Schumacher et al. [16] identified a LNR of $8 \%$ as a breakpoint for predicting the five-year OS and DFS in all stages of colon cancer. The survival analysis of stage III colon cancer patients revealed that a LNR of $18 \%$ was predictive of the five-year DFS [15]. Our study investigated the predictive value of the metastatic LNR for stage III rectal cancer, not colon cancer. No significant difference was detected between our two groups in terms of the OS and the DSF at the 5th, 4th, and 3rd years after surgery. This may be due to the limited number of patients in our study and the limited follow-up period. However, we found that a LNR of $15 \%$ was a cutoff point for predicting the two-year DFS. Because over $80 \%$ of recurrences in colorectal cancer usually occur in the first 2 years following surgery [38], we can conclude that our results show that the LNR has a good predictive value for recurrence of rectal cancer. Dekker et al. [36] showed that in addition to the 7th edition of the Union for International Cancer Control/AJCC TNM classification, the metastatic LNR was an independent prognostic factor for OS and local recurrence in stage III rectal cancer. In our study, the multivariate Cox analysis showed that the LNR was an independent prognostic factor for DFS in stage III rectal cancer. The metastatic LNR has been reported to be a better prognostic factor for survival in stage III rectal cancer than the currently-used lymphnode staging method in the TNM system [18, 32, 34]. A few studies recently investigated the LNR in rectal cancer and reported a significant correlation between the LNR and survival $[22,33,35$, $39,40]$. However, previous studies on the LNR in rectal cancer se- 
lected cutoff points arbitrarily [35]. We simply found a single LNR cutoff point in rectal cancer, which differentiates our study from other studies.

Our study differs from others investigating the LNR in that it used a single cutoff value for a comparison of higher and lower values. Previous studies were also different from this study in that they compared the prognostic values of the LNR and $\mathrm{N}$ staging by separating them into many groups, which produced unclear results $[33,35]$. We divided our patients into two groups. In addition, previous studies included all rectal cancer patients, even those having neoadjuvant therapy, in the analysis. We did not include this group of patients so as not to affect the number of metastatic lymph nodes. We found that all patients with LNR $<15 \%$ $(\mathrm{n}=21)$ had a stage pN1 tumor, but contrary to our expectation, patients with LNR $\geq 15 \%(\mathrm{n}=34)$ consisted of those with stage $\mathrm{pN} 1$ and $\mathrm{pN} 2$ tumors (N1, 13 patients; N2, 21 patients). We also found that patients with a stage $\mathrm{pN} 1$ tumor and LNR $\geq 15 \%$ had a two-year DFS of $61.5 \%$ (18.6 \pm 1.9 months). However, the patients with a $\mathrm{pN} 1$ tumor and LNR $<15 \%$ had a better two-year DFS of 95.2\% (23.0 \pm 0.95 months, $\mathrm{P}=0.023$ ) (Fig. 2). The two-year DFS in LNR $\geq 15 \%$ patients with a pN1 tumor was not significantly better than that in $\mathrm{LNR} \geq 15 \%$ patients with a pN2 tumor $(61.5 \%$ and $71.4 \%$, respectively, $\mathrm{P}=0.76$ ). This result supports reports that show the LNR to be a more accurate prognostic factor for survival in stage III rectal cancer than the currently-used lymphnode staging method in the TNM system. Similar results were shown by Park et al. [41] who showed that the five-year survival rates differed with the LNR in patients with N1-stage cancer. They also suggested that the five-year survival rates of the patients with N2-stage cancer were not different for a LNR with a cutoff of 7\%. Inoue et al. [9] and Bando et al. [10] insisted that the LNR was more meaningful for giving a prognosis because it reduced stage migration. These findings suggest that the LNR can replace $\mathrm{N}$ staging and that a revision of the current TNM staging is needed. Determination of the optimal approach to quantify the lymphnode status in colorectal cancer will help accurate patient staging, allow appropriate adjuvant treatment planning, and provide a better prediction of the long-term prognosis. This study supports recent studies showing that the LNR correlated with the prognosis.

In conclusion, our study showed the prognostic significance of a ratio-based staging system for rectal cancer. This may help in developing more accurate staging systems. In addition, we demonstrated that a ratio of $15 \%$ represents the LNR cutoff point for predicting a prognosis for patients with rectal cancer.

\section{CONFLICT OF INTEREST}

No potential conflict of interest relevant to this article was reported.

\section{REFERENCES}

1. Jemal A, Tiwari RC, Murray T, Ghafoor A, Samuels A, Ward E, et al. Cancer statistics, 2004. CA Cancer J Clin 2004;54:8-29.

2. Greene FL, Page DL, Fleming ID, Fritz AG, Balch CM, Haller DG, et al., editors. AJCC cancer staging manual. 6th ed. New York: Springer-Verlag; 2002.

3. Van Cutsem EJ, Oliveira J; ESMO Guidelines Working Group. Colon cancer: ESMO clinical recommendations for diagnosis, adjuvant treatment and follow-up. Ann Oncol 2008;19 Suppl 2:ii29-30.

4. Engstrom PF, Arnoletti JP, Benson AB 3rd, Chen YJ, Choti MA, Cooper HS, et al. NCCN Clinical Practice Guidelines in Oncology: rectal cancer. J Natl Compr Canc Netw 2009;7:838-81.

5. Beresford M, Glynne-Jones R, Richman P, Makris A, Mawdsley S, Stott $\mathrm{D}$, et al. The reliability of lymph-node staging in rectal cancer after preoperative chemoradiotherapy. Clin Oncol (R Coll Radiol) 2005;17:448-55.

6. Johnson PM, Malatjalian D, Porter GA. Adequacy of nodal harvest in colorectal cancer: a consecutive cohort study. J Gastrointest Surg 2002;6:883-88.

7. Noura S, Ohue M, Kano S, Shingai T, Yamada T, Miyashiro I, et al. Impact of metastatic lymph node ratio in node-positive colorectal cancer. World J Gastrointest Surg 2010;2:70-7.

8. Persiani R, Rausei S, Biondi A, Boccia S, Cananzi F, D’Ugo D. Ratio of metastatic lymph nodes: impact on staging and survival of gastric cancer. Eur J Surg Oncol 2008;34:519-24.

9. Inoue K, Nakane Y, Iiyama H, Sato M, Kanbara T, Nakai K, et al. The superiority of ratio-based lymph node staging in gastric carcinoma. Ann Surg Oncol 2002;9:27-34.

10. Bando E, Yonemura Y, Taniguchi K, Fushida S, Fujimura T, Miwa K. Outcome of ratio of lymph node metastasis in gastric carcinoma. Ann Surg Oncol 2002;9:775-84.

11. Weir L, Speers C, D'yachkova Y, Olivotto IA. Prognostic significance of the number of axillary lymph nodes removed in patients with node-negative breast cancer. J Clin Oncol 2002;20:1793-9.

12. Herr HW, Bochner BH, Dalbagni G, Donat SM, Reuter VE, Bajorin DF. Impact of the number of lymph nodes retrieved on outcome in patients with muscle invasive bladder cancer. J Urol 2002; 167:1295-8.

13. Berger AC, Watson JC, Ross EA, Hoffman JP. The metastatic/examined lymph node ratio is an important prognostic factor after pancreaticoduodenectomy for pancreatic adenocarcinoma. Am Surg 2004;70:235-40.

14. Gajra A, Newman N, Gamble GP, Kohman LJ, Graziano SL. Effect of number of lymph nodes sampled on outcome in patients with stage I non-small-cell lung cancer. J Clin Oncol 2003;21:1029-34.

15. Wang J, Hassett JM, Dayton MT, Kulaylat MN. Lymph node ratio: role in the staging of node-positive colon cancer. Ann Surg Oncol 2008;15:1600-8.

16. Schumacher P, Dineen S, Barnett C Jr, Fleming J, Anthony T. The metastatic lymph node ratio predicts survival in colon cancer. Am J Surg 2007;194:827-31.

17. Peschaud F, Benoist S, Julié C, Beauchet A, Penna C, Rougier P, et al. The ratio of metastatic to examined lymph nodes is a powerful independent prognostic factor in rectal cancer. Ann Surg 2008; 
248:1067-73.

18. Lee HY, Choi HJ, Park KJ, Shin JS, Kwon HC, Roh MS, et al. Prognostic significance of metastatic lymph node ratio in node-positive colon carcinoma. Ann Surg Oncol 2007;14:1712-7.

19. Derwinger K, Carlsson G, Gustavsson B. A study of lymph node ratio as a prognostic marker in colon cancer. Eur J Surg Oncol 20081;34:771-5.

20. Chin CC, Wang JY, Yeh CY, Kuo YH, Huang WS, Yeh CH. Metastatic lymph node ratio is a more precise predictor of prognosis than number of lymph node metastases in stage III colon cancer. Int J Colorectal Dis 2009;24:1297-302.

21. Rosenberg R, Friederichs J, Schuster T, Gertler R, Maak M, Becker $\mathrm{K}$, et al. Prognosis of patients with colorectal cancer is associated with lymph node ratio: a single-center analysis of 3,026 patients over a 25-year time period. Ann Surg 2008;248:968-78.

22. Peng J, Xu Y, Guan Z, Zhu J, Wang M, Cai G, et al. Prognostic significance of the metastatic lymph node ratio in node-positive rectal cancer. Ann Surg Oncol 2008;15:3118-23.

23. Baxter NN, Virnig DJ, Rothenberger DA, Morris AM, Jessurun J, Virnig BA. Lymph node evaluation in colorectal cancer patients: a population-based study. J Natl Cancer Inst 2005;97:219-25.

24. Goldstein NS. Lymph node recoveries from 2427 pT3 colorectal resection specimens spanning 45 years: recommendations for a minimum number of recovered lymph nodes based on predictive probabilities. Am J Surg Pathol 2002;26:179-89.

25. Greene FL, Stewart AK, Norton HJ. New tumor-node-metastasis staging strategy for node-positive (stage III) rectal cancer: an analysis. J Clin Oncol 2004;22:1778-84.

26. Gunderson LL, Jessup JM, Sargent DJ, Greene FL, Stewart A. Revised tumor and node categorization for rectal cancer based on surveillance, epidemiology, and end results and rectal pooled analysis outcomes. J Clin Oncol 2010;28:256-63..

27. Wong SL, Ji H, Hollenbeck BK, Morris AM, Baser O, Birkmeyer JD. Hospital lymph node examination rates and survival after resection for colon cancer. JAMA 2007;298:2149-54.

28. Evans MD, Barton K, Rees A, Stamatakis JD, Karandikar SS. The impact of surgeon and pathologist on lymph node retrieval in colorectal cancer and its impact on survival for patients with Dukes' stage B disease. Colorectal Dis 2008;10:157-64.

29. Mekenkamp LJ, van Krieken JH, Marijnen CA, van de Velde CJ, Nagtegaal ID; Pathology Review Committee and the Co-operative Clinical Investigators. Lymph node retrieval in rectal cancer is dependent on many factors: the role of the tumor, the patient, the surgeon, the radiotherapist, and the pathologist. Am J Surg
Pathol 2009;33:1547-53.

30. Shin JY, Hong KH. Prognostic significance of lymph node ratio in stage III rectal cancer. J Korean Soc Coloproctol 2011;27:252-9.

31. Gunderson LL, Jessup JM, Sargent DJ, Greene FL, Stewart AK. Revised TN categorization for colon cancer based on national survival outcomes data. J Clin Oncol 2010;28:264-71.

32. Berger AC, Sigurdson ER, LeVoyer T, Hanlon A, Mayer RJ, Macdonald JS, et al. Colon cancer survival is associated with decreasing ratio of metastatic to examined lymph nodes. J Clin Oncol 2005;23:8706-12.

33. Kobayashi H, Mochizuki H, Kato T, Mori T, Kameoka S, Shirouzu $\mathrm{K}$, et al. Lymph node ratio is a powerful prognostic index in patients with stage III distal rectal cancer: a Japanese multicenter study. Int J Colorectal Dis 2011;26:891-6.

34. De Ridder M, Vinh-Hung V, Van Nieuwenhove Y, Hoorens A, Sermeus A, Storme G. Prognostic value of the lymph node ratio in node positive colon cancer. Gut 2006;55:1681.

35. Kim YS, Kim JH, Yoon SM, Choi EK, Ahn SD, Lee SW, et al. Lymph node ratio as a prognostic factor in patients with stage III rectal cancer treated with total mesorectal excision followed by chemoradiotherapy. Int J Radiat Oncol Biol Phys 2009;74:796802.

36. Dekker JW, Peeters KC, Putter H, Vahrmeijer AL, van de Velde CJ. Metastatic lymph node ratio in stage III rectal cancer; prognostic significance in addition to the 7th edition of the TNM classification. Eur J Surg Oncol 2010;36:1180-6.

37. Wichmann MW, Muller C, Meyer G, Strauss T, Hornung HM, Lau-Werner U, et al. Effect of preoperative radiochemotherapy on lymph node retrieval after resection of rectal cancer. Arch Surg 2002;137:206-10.

38. Kraemer M, Wiratkapun S, Seow-Choen F, Ho YH, Eu KW, Nyam D. Stratifying risk factors for follow-up: a comparison of recurrent and nonrecurrent colorectal cancer. Dis Colon Rectum 2001; 44:815-21.

39. Stocchi L, Nelson H, Sargent DJ, O’Connell MJ, Tepper JE, Krook JE, et al. Impact of surgical and pathologic variables in rectal cancer: a United States community and cooperative group report. J Clin Oncol 2001;19:3895-902.

40. Moug SJ, Saldanha JD, McGregor JR, Balsitis M, Diament RH. Positive lymph node retrieval ratio optimises patient staging in colorectal cancer. Br J Cancer 2009;100:1530-3.

41. Park YH, Lee JI, Park JK, Jo HJ, Kang WK, An CH. Clinical significance of lymph node ratio in stage III colorectal cancer. J Korean Soc Coloproctol 2011;27:260-5. 